\title{
A Bibliometric Review of Research on STEM Education in ASEAN: Science Mapping the Literature in Scopus Database, 2000 to 2019
}

\author{
Cao Thi Ha ${ }^{1}$, Trinh Thi Phuong Thao ${ }^{1 *}$, Nguyen Tien Trung ${ }^{2,3}$, Le Thi Thu Huong ${ }^{1}$, Ngo Van Dinh ${ }^{4}$, \\ Tran Trung ${ }^{5}$ \\ 1 Thai Nguyen University of Education, Thai Nguyen University, Thai Nguyen, VIETNAM \\ ${ }^{2}$ Institute of Theoretical and Applied Research (ITAR), Duy Tan University, Hanoi, VIETNAM \\ ${ }^{3}$ Vietnam Journal of Education, Hanoi, VIETNAM \\ ${ }^{4}$ Culture School - Training Department, Ministry of Public Security, Thai Nguyen, VIETNAM \\ ${ }^{5}$ Vietnam Academy for Ethnic Minorities, Hanoi, VIETNAM
}

Received 16 July 2020 - Accepted 27 August 2020

\begin{abstract}
In recent years, Science, Technology, Engineering, and Math (STEM) education has become important in many countries around the world. In this study a bibliometric analysis was applied to evaluate the scientific results of STEM education in the Association of Southeast Asian Nations (ASEAN) region, indexed in the Scopus database for the period 2000-2019. A total of 175 publications were taken from the Scopus database for analysis. Our main findings show that the trend of research in this field has shown a dramatic increase in scientific production in the last three years, when the published amount accounted for $67.43 \%$ of the collection. Authors with the most publications came from the top 10 universities and research institutes (accounting for 38.44\%). Scholars in the ASEAN region tend to submit their works to Q3 and Q4 journals in the $\mathrm{SClmago}$ database. Diverse research with basic and cross-cutting topics focus on STEM education for undergraduate students, engineering education, and education computing.
\end{abstract}

Keywords: ASEAN, bibliometrics, biblioshiny, scientometrics, STEM education, VOSviewer

\section{INTRODUCTION}

STEM education is an interdisciplinary approach in the learning process, in which the principle academic concepts are integrated with real-world lessons. STEM education helps students apply their knowledge in science, technology, engineering and mathematics into specific contexts, helping to connect schools, communities, workplaces and global organizations, thereby developing STEM capabilities for competition in the new economy (Hsu \& Fang, 2019; Le et al., 2019). The development of STEM education has a positive impact on academic achievement and the development of various skills for students (Batdi et al., 2019). In recent years, STEM education has become both important in many countries around the world and the concern of many policymakers. In many countries, the economic and social benefits of scientific thinking and STEM education are widely believed to have broad applications for workers in both STEM and non-STEM occupations. As such, many contemporary policymakers consider widespread STEM literacy, as well as specific STEM expertise, to be critical human capital competencies for a 21st-century economy (Gonzalez \& Kuenzi, 2014; Hsu \& Fang, 2019).

The basic bibliometric analysis uses descriptive statistics to document "topographical" trends within a body of knowledge (Hallinger \& Kovačević, 2019) . In recent years there have been researches on scientific bibliometric analysis of STEM education in the world via the Web of Science database (Aksoy, 2018; Batdi et al., 2019; Özkaya, 2019; Yu et al., 2016). These researches have drawn a complete picture of the formation and development of STEM education's researches and applications. There has been a rapid increase in the number of STEM education researches during the previous decade; Academic interest in STEM in education rocketed after 2008 ( $93.3 \%$ of the publications

(c) 2020 by the authors; licensee Modestum. This article is an open access article distributed under the terms and conditions of the Creative Commons Attribution License (http://creativecommons.org/licenses/by/4.0/).

$\square$ hact@tnue.edu.vn $\square$ trinhthao.sptn@gmail.com ( ${ }^{*}$ Correspondence) $\square$ ntt.vje@gmail.com $\nabla$ lethithuhuong@tnue.edu.vn \nvdinh81anh@gmail.com $\boldsymbol{\Delta}$ trungt1978@gmail.com 


\section{Contribution to the literature}

- Overview of the development of research in STEM education in ASEAN.

- The collaboration of STEM education researchers in the ASEAN region.

- The main research directions for STEM education and their development during this period.

related to STEM education were formed by the works published between 2008-2017). It can be seen that the countries that contributed most to STEM education during 1992-2013 were developed countries: The United States, England, The Netherlands, Australia (Özkaya, 2019; Yu et al., 2016). Of these, the US is the nation that realized the highest number of collaborations with other countries, while England is guiding the researches that will be made in the STEM education subject area (Özkaya, 2019). This can be explained partly by the increasing number and funding of STEM education projects in the US (a total of 127 projects funded by the US Department of Education's Institute of Educational Sciences (IES) from 2003 to 2019) (Li et al., 2020). STEM educational publications mainly focus on Q1 journals in the SCImago database, such as the International Journal of Science Education, the Journal of Science Education and Technology, the Journal of Engineering Education, and teachers' college records with the STEM keywords: science education, STEM education, and higher education (Özkaya, 2019; Yu et al., 2016).

The Association of South East Asian Nations (ASEAN) was established on August 8, 1967 in Bangkok by the five original member states: Indonesia, Malaysia, Philippines, Singapore, and Thailand. Today, the membership includes 10 States: Brunei Darussalam, Cambodia, Indonesia, Laos, Malaysia, Myanmar, Philippines, Singapore, Thailand, and Vietnam, in addition to one Observer - Papua New Guinea. ASEAN researches have attracted the attention and scholarly debate of both regional and international scholars, but academic researches on ASEAN are limited because research parameters are always locked in issues related to economy, politics, security, and trade development in the region. The issue of education in the ASEAN region is a subject of little research (Koh, 2007).

From the previous researches, it can be seen that the research on STEM education has increased sharply in recent years in developed countries and has had a positive impact on the development of student's skills to meet the needs of highly skilled labor (Friedman, 2005; Halim et al., 2018; Promjan \& Ditcharoen, 2019). However, previous studies have not mentioned the importance of STEM education research in the ASEAN region. Therefore, the main objective of this study is to explore the current state of STEM education research in ASEAN countries by using bibliographic data extracted from the Scopus database from 2000 to 2019. This study is to answer the following questions.
1. What is the overview of research development in the field of STEM education in ASEAN?

2. With which partner countries are ASEAN scholars cooperating most in this period?

3. What are the main research directions and developmental trends during this period?

Results from this study provide information that may be useful for research institutions in ASEAN countries. It is also especially relevant for decision makers preparing future plans and grants to support the development of STEM education research in the ASEAN region for the purpose of meeting international quality.

\section{METHODS}

In this study we followed the general bibliometric analysis workflow that consists of five stages: 1) Study Design; 2) Data Collection; 3) Data Analysis; 4) Data Visualization; and 5) Interpretation (Börner et al., 2003; Zupic \& Čater, 2015).

In the study design stage our main research question was: What was the bibliometric of publications in STEM Education, which were published by scholars with ASEAN affiliations, and indexed in the Scopus database for the 2000-2019 period.

Data collection stage is divided into three sub-stages: data collection, data filtering, and data cleaning.

Step 1: Data Collection. The author team performed a search from the Scopus database (http://www.scopus.com) with advanced search options to ensure search terms and operators matched the syntax of the search tool.

Affiliation Country is defined as all ASEAN member countries; Year of Publication was selected in the period from 2000 to 2019.

Searching keyword for the field of STEM education included: STEM or a combination of words (educat ${ }^{\star}$ OR learn* OR teach*) and words (science* AND technolog* AND engineer* AND mathematic*). The symbol “*” represents any group of characters in the Scopus data search syntax. Search is limited to summary, keywords, and document titles.

Document types are limited to: articles, conference papers, and reviews in the field of social sciences, written in English.

Query strings query data through Scopus as follows:

AFFILCOUNTRY ("Viet nam" OR vietnam OR singapore OR brunei OR malaysia OR thailand OR philippines OR indonesia OR laos OR myanmar OR 
cambodia) AND (PUBYEAR > 1999 AND PUBYEAR < 2020) AND TITLE-ABS-KEY((educat* OR learn* OR teach $\left.^{*}\right)$ AND ((science* AND technolog* AND engineer* AND mathematic*) OR (STEM\})) AND SUBJAREA (soci) AND (LIMIT-TO (DOCTYPE , "ar") OR LIMIT-TO (DOCTYPE , “cp") OR LIMIT-TO (DOCTYPE , “re”)) AND (LIMIT-TO (LANGUAGE , "English”))

Obtained result included 220 documents (* Data collected on May 15, 2020).

Step 2: Data Filtering. We conducted data filtering by censoring titles, abstracts, and keywords, removing materials that are not related to STEM education. After filtering the data, the number of remaining records was 175. With this list, we conducted initial analysis on tools provided by Scopus to collect additional information about authors, affiliations, and journals. For further analysis we extracted the information from the search results into CSV format (file .csv) and Bitext (file .bib) to perform analysis on bibliometric tools.

Step 3: Data Cleaning. Downloaded data needed to be cleaned because the quality of analysis depends very much on the quality of input data. Some data errors have been corrected in this extra period. For example, "Viet nam" and "Vietnam" were corrected as one country, "Universiti Kebangsaan Malaysia" and "Kembangan Malaysia University" were corrected as one affiliation, etc.

Measurements were conducted on this data. Various analytical techniques have been applied to extract the information about the collection of publications. General statistics provide quantitative information such as the number of annual publications and publication trends, journals with the top number of publications, and authors or organizations with the highest productivity. Co-authoring across countries has been analyzed to research the collaboration among the most productive countries in the field of research. Synonym analysis of keywords, titles, and abstracts was conducted to identify the most important research topics and trends. Many tools were used in the data visualization stage. The most used software programs were BibExcel (Persson, 2009), VOSviewer (van Eck \& Waltman, 2010), CitNetExplorer (van Eck \& Waltman, 2014), SciMAT (Cobo et al., 2012), and Bibliometrix (Aria \& Cuccurullo, 2017).

To analyze the data obtained in this paper two main software programs were used: Bibliometrix and VOSviewer. In addition, Microsoft Excel was used to summarize data in different stages. A website that runs Scopus data to calculate two metrics (SCImago Journal Rank (SJR) and Source Normalized Impact per Paper (SNIP)) was also used, which was directly compared to Web of Knowledge's Impact Factor: (https:/ / www.scimagojr.com/) to analyze the quality of journals.
Table 1. Main information regarding the collection in the field of STEM education in ASEAN

\begin{tabular}{lc}
\hline Description & Results \\
\hline Documents & 175 \\
Sources (Journals, Books, etc.) & 92 \\
Keywords Plus (ID) & 525 \\
Author's Keywords (DE) & 557 \\
Period & $2007-2019$ \\
Average citations per documents & 3.589 \\
Authors & 504 \\
Author Appearances & 638 \\
Authors of single-authored documents & 14 \\
Authors of multi-authored documents & 490 \\
Single-authored documents & 16 \\
Documents per Author & 0.347 \\
Authors per Document & 2.88 \\
Co-Authors per Documents & 3.65 \\
Collaboration Index & 3.08 \\
Document types & \\
ARTICLE & 107 \\
CONFERENCE PAPER & 68 \\
\hline
\end{tabular}

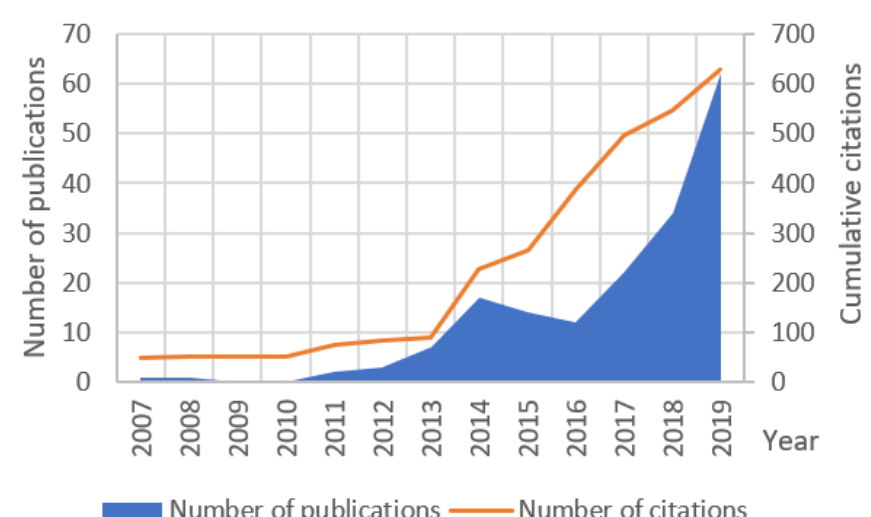

Figure 1. Annual number of publications and its cumulative citation values in the field of STEM education in ASEAN

\section{RESULTS}

\section{Publication Output and Growth Trend}

The search results show that from 2000 to 2006 there were no articles about STEM education in ASEAN. The main information related to STEM Education publications in 2007-2019 in ASEAN is presented in Table 1. The number of published papers related to ASEAN is 175 (107 articles and 68 conference papers) over the past 12 years.

The number of authors researching this issue is 504; Average citations per documents: 3.589. The ratio of Authors per Document of ASEAN is 2.88; Annual growth rate according to statistics from Biblioshiny software: $51.09 \%$.

Figure 1 shows the number of articles published each year with the corresponding cumulative number of citations. The interest of scientists on this issue has only focused in the past 4 years with a rapid increase in number of articles. 


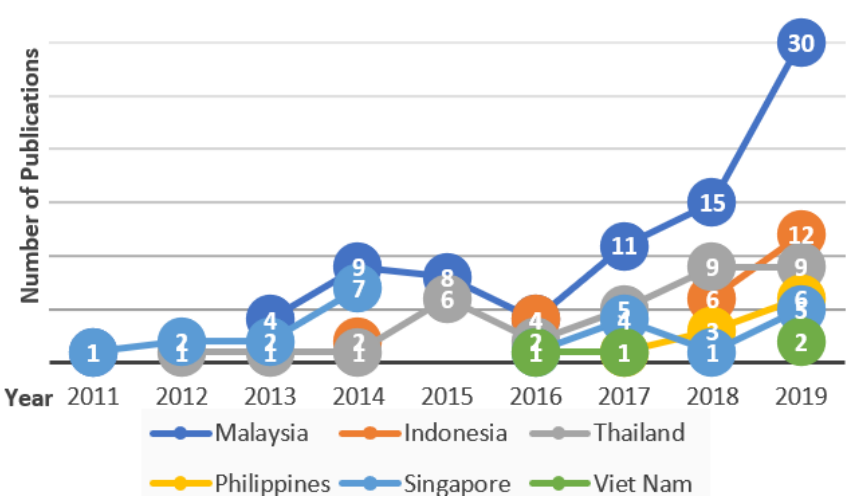

Figure 2. Number of articles by country (from 2011 to 2019) in the field of STEM education

This figure shows that the first articles on STEM education research in the ASEAN region appeared in 2007 and increased in number gradually until 2014 (17 articles); from 2017 to 2019 there was a noticeable surge with a peak of 62 articles. Accumulated citations did not increase much in the 2007-2013 period, but from 2014 onward citations soared rapidly with the increase in publications. However, the number of citations increased much more slowly than the rate of increase of the number of articles.

\section{Contribution by Nations}

The total number of documents listed is 175 , of which ASEAN countries have contributed according to their number of articles as follows: Malaysia (83); Thailand (35); Indonesia (24); Singapore (23); Philippines (10); Vietnam (4) and Cambodia (1). In this list, there are no authors from Brunei Darussalam, Laos, or Myanmar (The number of articles is counted for the country or research organization if the article was conducted by one or more authors from such country or organization, regardless of how many co-authors were not belonging to that organization or country).

Figure 2 shows the number of articles by country (from 2011 to 2019) in the field of STEM education. It can be seen that Malaysia has a remarkable contribution compared to the rest of the region in this field. The number of publications on this topic increases annually (except for 2016). Thailand and Singapore are also countries that frequently pay attention to this topic when there are annual publications, however, their numbers only increased modestly. Other nations have also researched STEM education but their contributions are not continuous. The year 2019 recorded the largest number of publications, by country respectively: Malaysia (30), Indonesia (12), Thailand (9), Philippines (6), Singapore (5) and Vietnam (2).

The academic cooperation on STEM education research among ASEAN countries and other countries in the world is shown in Figure 3. For each of the 26 countries, the total strength of the co-authorship links with other countries will be calculated. The countries with the greatest total link strength will be selected.

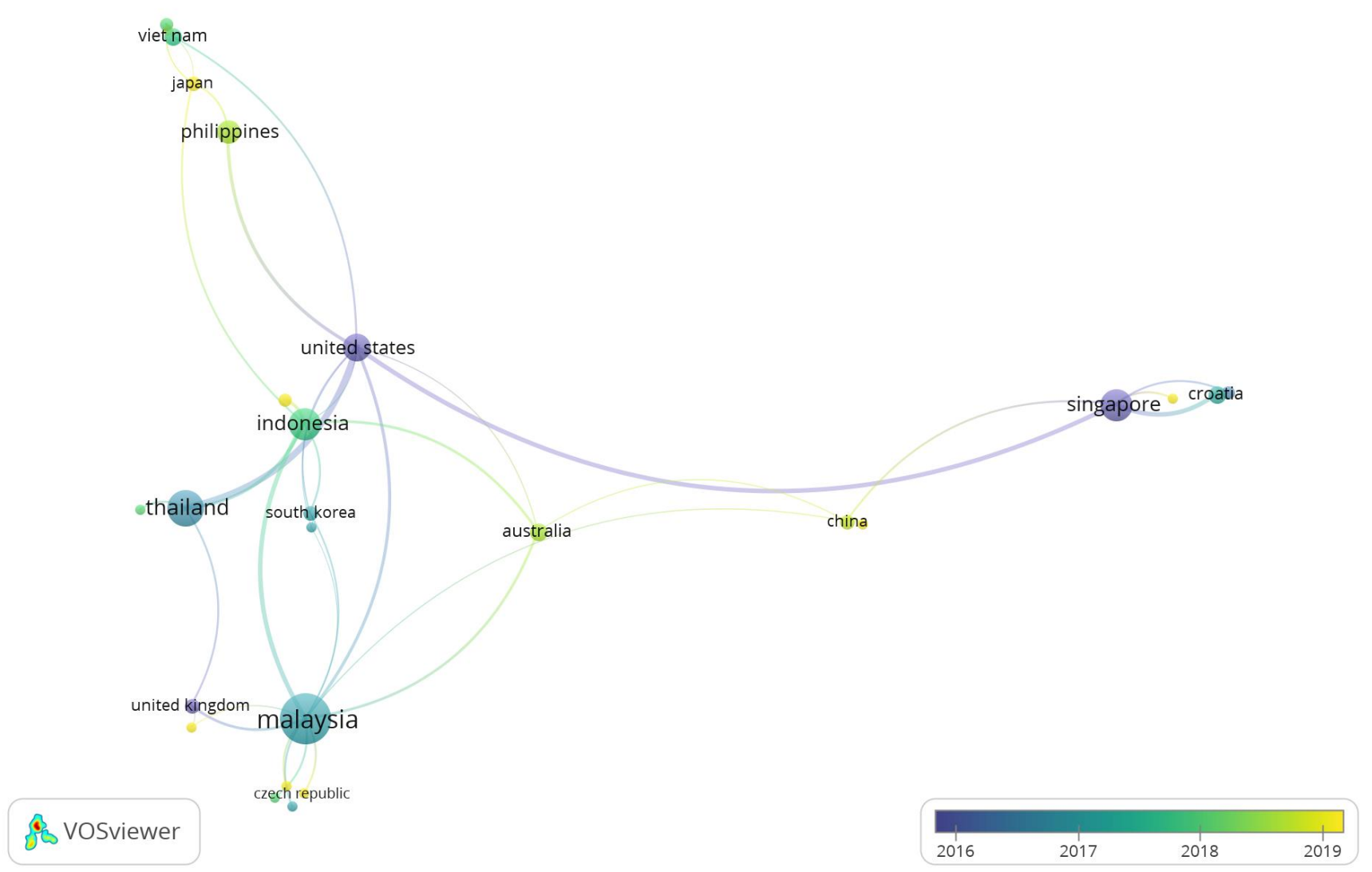

Figure 3. Cooperation network between partner countries and ASEAN in the field of STEM education 
Table 2. Top 10 most productive affiliations publishing in the field of STEM education in ASEAN

\begin{tabular}{|c|c|c|c|c|c|c|c|}
\hline Order & Affiliations & Country & Articles & 2016 & 2017 & 2018 & 2019 \\
\hline 1 & University Kebangsaan Malaysia (UKM) & Malaysia & 23 & 2 & 2 & 3 & 7 \\
\hline 2 & University Teknologi Malaysia (UTM) & Malaysia & 20 & 1 & 3 & 5 & 7 \\
\hline 3 & Nanyang Technological University (NTU) & Singapore & 16 & & 2 & & 3 \\
\hline 4 & National Institute of Education (NIE) & Singapore & 11 & & 2 & & 2 \\
\hline 5 & Khon Kaen University (KKU) & Thailand & 8 & & & 4 & \\
\hline 6 & King Mongkut's University of Technology North Bangkok (KMUTNB) & Thailand & 7 & 1 & 2 & 2 & 2 \\
\hline 7 & University Sains Malaysia (USM) & Malaysia & 6 & & & 1 & 4 \\
\hline 8 & King Mongkut's University of Technology Thonburi (KMUTT) & Thailand & 6 & 1 & 1 & & 3 \\
\hline 9 & University of Malaya (UM) & Malaysia & 6 & & & 1 & 2 \\
\hline 10 & University Tunku Abdul Rahman (UTAR) & Malaysia & 5 & & 1 & 1 & 2 \\
\hline 10 & University Pendidikan Sultan Idris (UPSI) & Malaysia & 5 & & & 1 & 2 \\
\hline 10 & Sunway University (SU) & Malaysia & 5 & & 2 & 1 & \\
\hline
\end{tabular}
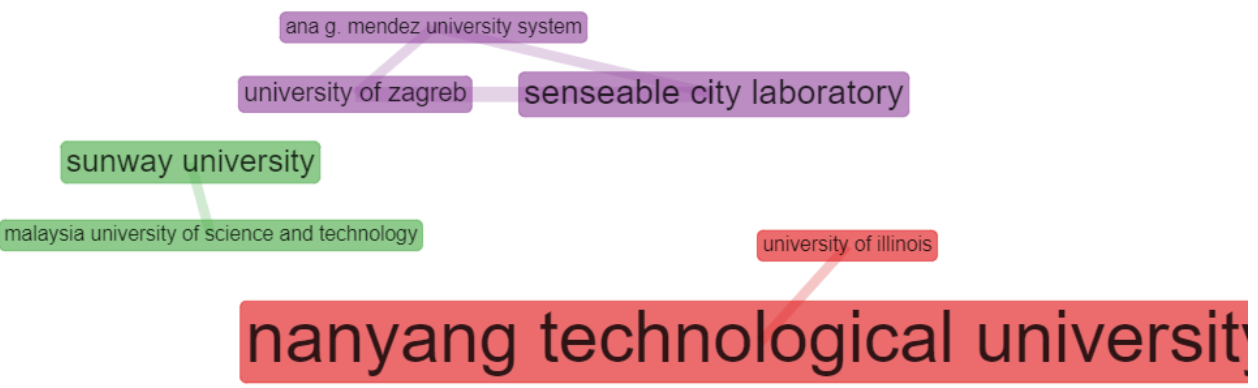

the national university of malaysia

universiti putra malaysia

universiti tunku abdul rahman

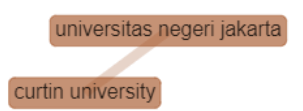

Figure 4. Cooperation between affiliations in the field of STEM education in ASEAN

Number of countries to be selected is 26. Minimum number of documents of a country: 1 .

As the diagram shows Malaysia has the most publications and has research cooperation in the field of STEM education with many other countries such as: Indonesia, the United States, Australia, and the Czech Republic. The authors from Thailand and Singapore cooperate mainly with authors from the United States in addition to some few other countries.

\section{Contribution by Institutions}

Table 2 shows the top 10 affiliations with the number of articles published in STEM education research in ASEAN.

There are 12 affiliations in this list ( 3 of which have 5 articles published). Of these, distributed by country, Malaysia has 7 affiliations (UKM, UTM, USM, UM, UTAR, UPSI, and SU), Thailand has 3 affiliations (KKU, KMUTNB, and KMUTT), Singapore has 2 (NTU and NIE). UKM is the affiliation with the largest number of publications with 23 publications, followed by: UTM (20), NTU (16), NIE (11), and KKE (8).

Table 2 records an increase in the number of publications published in 2018 and 2019.
The collaboration between STEM affiliations in ASEAN is shown in Figure 4. The diagram was created by Biblioshiny software using the data described in the methodology section. The figure shows six groups of affiliations that have collaborations. However, collaborations in research on the topic mainly stem from groups of authors working in 2 or 3 affiliations.

\section{Contribution by Journals}

When analyzing this content, the authors eliminated the number of Conference Paper documents to focus on Articles (107 publications). Table 3 describes the quality of the 10 journals with the highest number of articles related to STEM education in ASEAN.

These journals are sorted by quality in Scopus categories: Q2 (4), Q3 (3), Q4 (2), Not Classified (1). It was discovered that there are 3 journals from Turkey and 2 journals from The United States. There is only 1 journal from ASEAN (Journal Pendidikan IPA Indonesia). "Eurasia Journal of Mathematics Science and Technology Education" and "Journal Pendidikan IPA Indonesia" are the journals which are most used by authors, each with 8 articles. 
Table 3. Top 10 most active journals publishing in the field of STEM education in ASEAN

\begin{tabular}{|c|c|c|c|c|c|c|c|}
\hline Order & Journals & $\begin{array}{l}\text { Nation of } \\
\text { journals }\end{array}$ & $\begin{array}{l}\text { No. of } \\
\text { articles }\end{array}$ & $\begin{array}{l}\text { Cite } \\
\text { Score } \\
2019^{*}\end{array}$ & $\begin{array}{c}\text { SJR } \\
2018^{*}\end{array}$ & 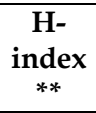 & $\begin{array}{l}\text { Scopus } \\
\text { quartile** }\end{array}$ \\
\hline 1 & $\begin{array}{l}\text { Eurasia Journal of Mathematics Science and Technology } \\
\text { Education }\end{array}$ & Turkey & 8 & 1.62 & 0.325 & 25 & Q3 \\
\hline 2 & Journal Pendidikan IPA Indonesia & Indonesia & 8 & 1.99 & 0.254 & 8 & Q3 \\
\hline 3 & Journal of Baltic Science Education & Lithuania & 6 & 1.23 & 0.387 & 12 & Q2 \\
\hline 4 & Journal of Turkish Science Education & Turkey & 5 & 1.6 & 0.314 & 11 & $\widehat{Q} 3$ \\
\hline 5 & Theory into Practice & United States & 4 & 1.71 & 0.522 & 50 & Q2 \\
\hline 6 & International Journal of Emerging Technologies in Learning & Germany & 3 & 1.45 & 0.219 & 15 & $\widehat{\mathrm{Q}} 2$ \\
\hline 7 & International Journal of Innovation Creativity and Change & United Kingdom & 3 & 6.89 & 0.187 & 4 & $\widehat{\mathrm{Q}} 4$ \\
\hline 8 & Journal for The Education of Gifted Young Scientists & Turkey & 3 & 2.07 & 0.141 & 3 & $\mathrm{Q} 4$ \\
\hline 9 & Universal Journal of Educational Research & United States & 3 & 0.21 & - & - & Not Classified \\
\hline 10 & Sustainability Switzerland & Switzerland & 2 & 3.08 & 0.549 & 53 & Q2 \\
\hline
\end{tabular}

* According to Scopus (http:/ / www.scopus.com) dated May 15, 2020

** According to SCImago Journal \& Country Rank (https:/ / www.scimagojr.com/) dated May 15, 2020

Table 4. Top 10 most productive authors publishing in the field of STEM education in ASEAN

\begin{tabular}{|c|c|c|c|c|c|c|}
\hline Order & Authors & Institutions $^{* *}$ & Country & $\begin{array}{c}\text { Number } \\
\text { of articles* }\end{array}$ & $\begin{array}{c}\text { H- } \\
\text { index }\end{array}$ & $\begin{array}{c}\text { Total } \\
\text { citations** }\end{array}$ \\
\hline 1 & Osman, Kamisah & Universiti Kebangsaan Malaysia & Malaysia & 9 & 12 & 443 \\
\hline 1 & Halim, Lilia Bt & Universiti Kebangsaan Malaysia & Malaysia & 9 & 9 & 437 \\
\hline 3 & Wongwatkit, Charoenchai & Mae Fah Luang University & Thailand & 6 & 5 & 52 \\
\hline 4 & Ibrahim, Nor Hasniza & Universiti Teknologi Malaysia & Malaysia & 5 & 4 & 93 \\
\hline 5 & Chien-Sing, Lee & Sunway University & Malaysia & 5 & 11 & 495 \\
\hline 6 & Srisawasdi, Niwat & Khon Kaen University & Thailand & 5 & 9 & 259 \\
\hline 7 & Teo, Tang Wee & National Institute of Education & Singapore & 5 & 5 & 122 \\
\hline 8 & Abdullah, Abdul Halim & Universiti Teknologi Malaysia & Malaysia & 4 & 7 & 160 \\
\hline 9 & Abdullah, Zaleha Binti & Universiti Teknologi Malaysia & Malaysia & 4 & 5 & 67 \\
\hline 10 & Bojić, Iva & Singapore-MIT Alliance for Research and Technology & Singapore & 4 & 11 & 451 \\
\hline
\end{tabular}

${ }^{*}$ Number articles in the field of STEM education in ASEAN

** According to Scopus (http://wwww.scopus.com) dated May 15, 2020

\section{Top-Authors' Production over the Time}

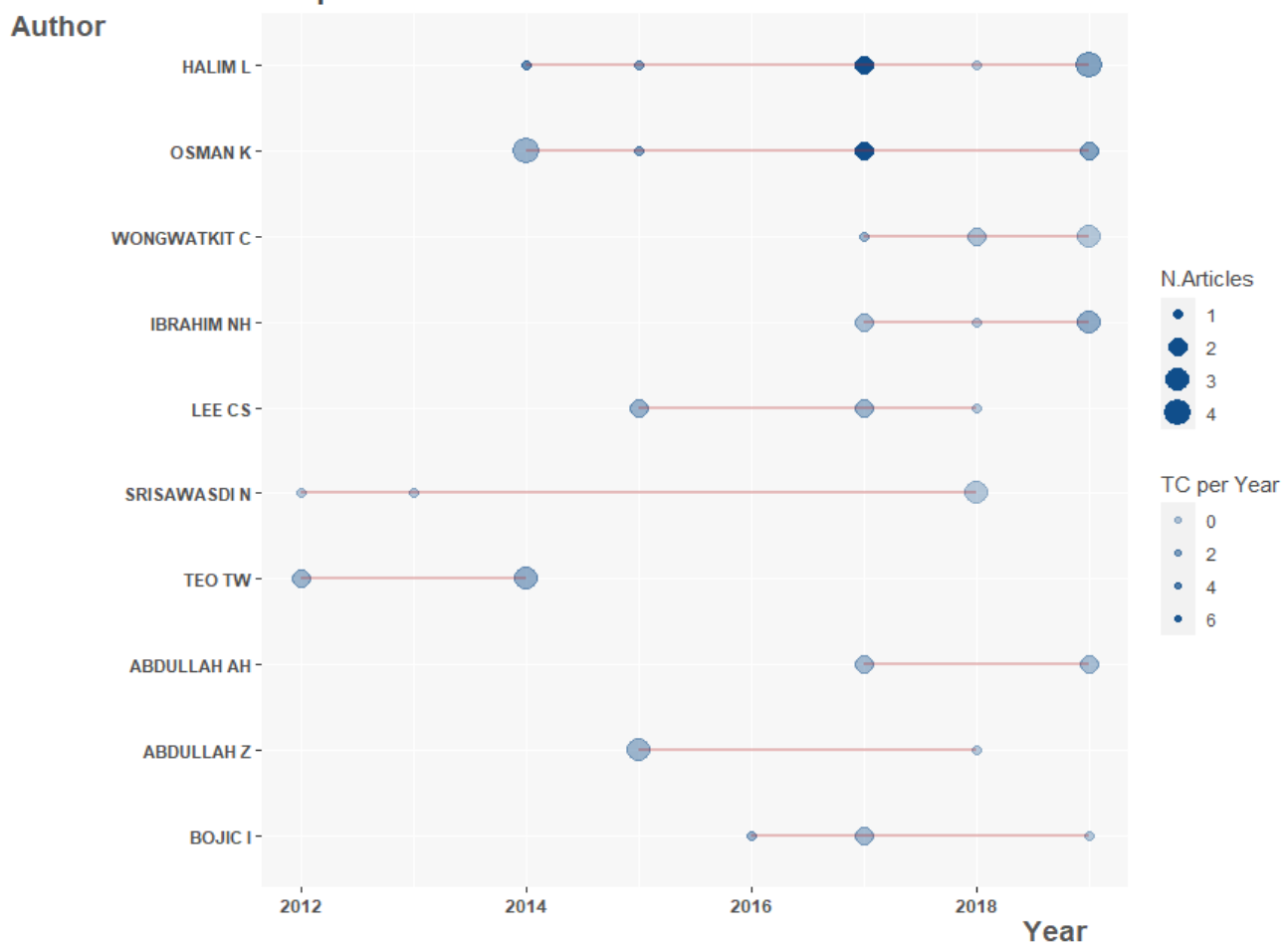

Figure 5. Annual publications of the 10 most productive authors in the field of STEM education in ASEAN

\section{Contribution by Authors}

Table 4 discloses crucial data concerning important information regarding the 10 authors with the highest number of published works related to STEM education in ASEAN and Figure 5 shows the number of annual publications of such authors. 


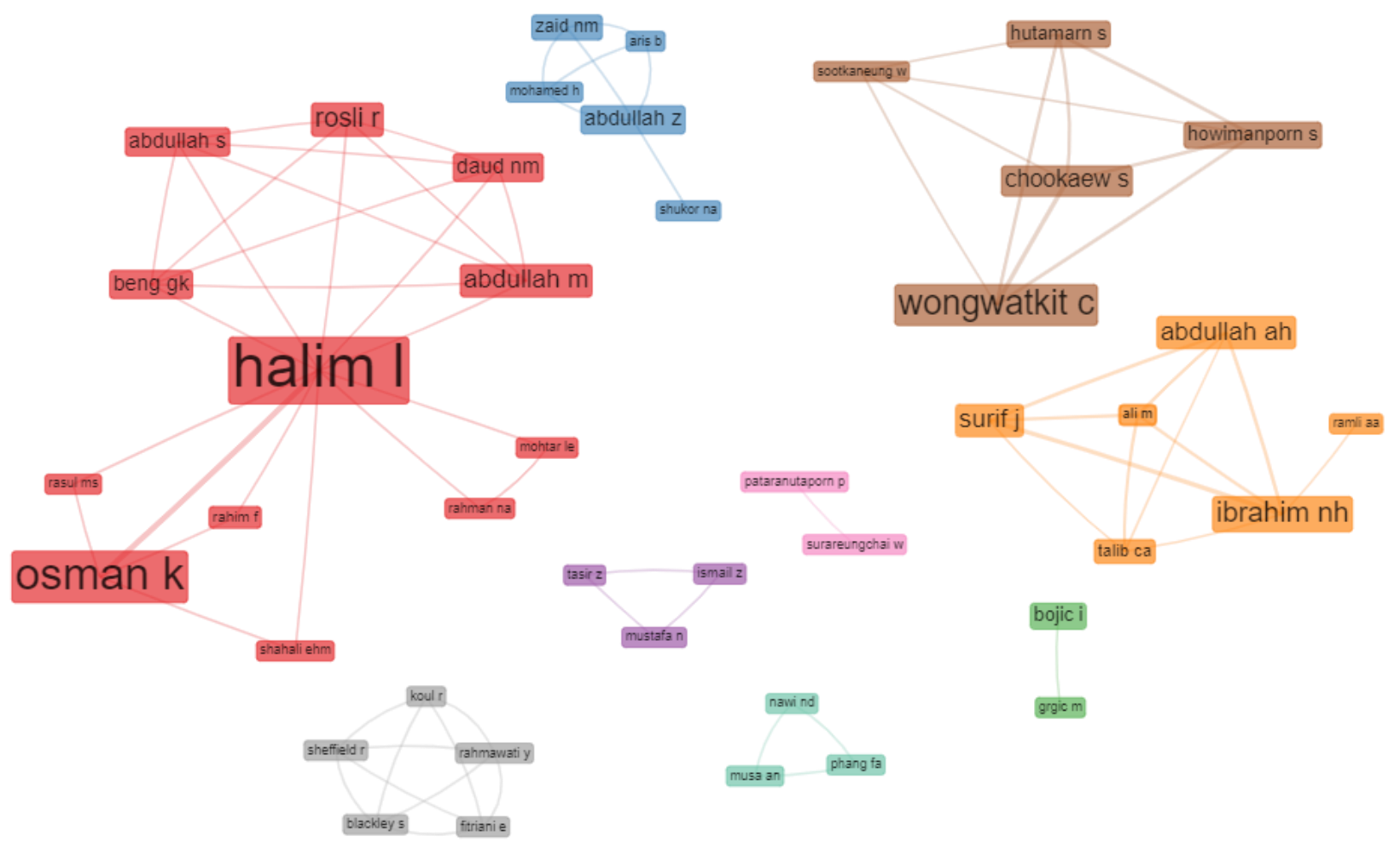

Figure 6. Collaborative network among authors in the field of STEM education in ASEAN

The most published authors are Osman Kamisah and Halim Lilia Bt, both whom come from University Kebangsaan Malaysia with 9 articles. There are 4 authors with a total citations index greater than 400 . In this list the distribution by country is: Malaysia (6), Singapore (2), Thailand (2).

According to Figure 5, we also see that the two authors with the largest number of published studies, Osman, Kamisah and Halim Lilia Bt, have continuously conducted researches on STEM education in ASEAN from 2014 to present. The authors in the Top 10 have dedicated their attention to this issue during the past 3 to 4 years. Teo Tang Wee (National Institute of Education, Singapore) has not published on this topic since 2014.

Collaboration among author groups is shown in Figure 6. The diagram was created with Biblioshiny software using the data described in the methodology section.

There are 9 groups of authors who collaborate on the topic, of which 4 research groups have the most publications. These have Osman Kamisah, Halim Lilia Bt, Wongwatkit Charoenchai (Mae Fah Luang University, Thailand) and Ibrahim Nor Hasniza (Universiti Teknologi Malaysia) as group research leaders. This diagram also shows the research collaboration between the two groups led by research group leaders from the University Kebangsaan Malaysia, Osman Kamisah and Halim Lilia Bt.

\section{Terms Analysis}

Figure 7 describes the keyword network analyzed by the VOSViewer software. The type of analysis is Cooccurrence analysis: The relatedness of items is determined based on the number of documents in which they occur together. The minimum number of documents of a keyword is 3 .

Figure 7 demonstrates the relationships between research topics through keywords. In addition, this figure also shows the research interests in the articles analyzed between 2015 and 2019.

Figure 8 shows a Words cloud based on the keywords of the publications on STEM of ASEAN countries according to the list of enumerated keywords. The author has removed keywords directly related to the search content described in the research method section such as: STEM, STEM (science, technology, engineering and mathematics), STEM education, education, etc.

The words cloud above shows the frequency of words appearing in the articles' keywords in descending order: Students, Engineering Education, Education Computing, Surveys, Teaching, E-learning, Learning Systems, etc. 


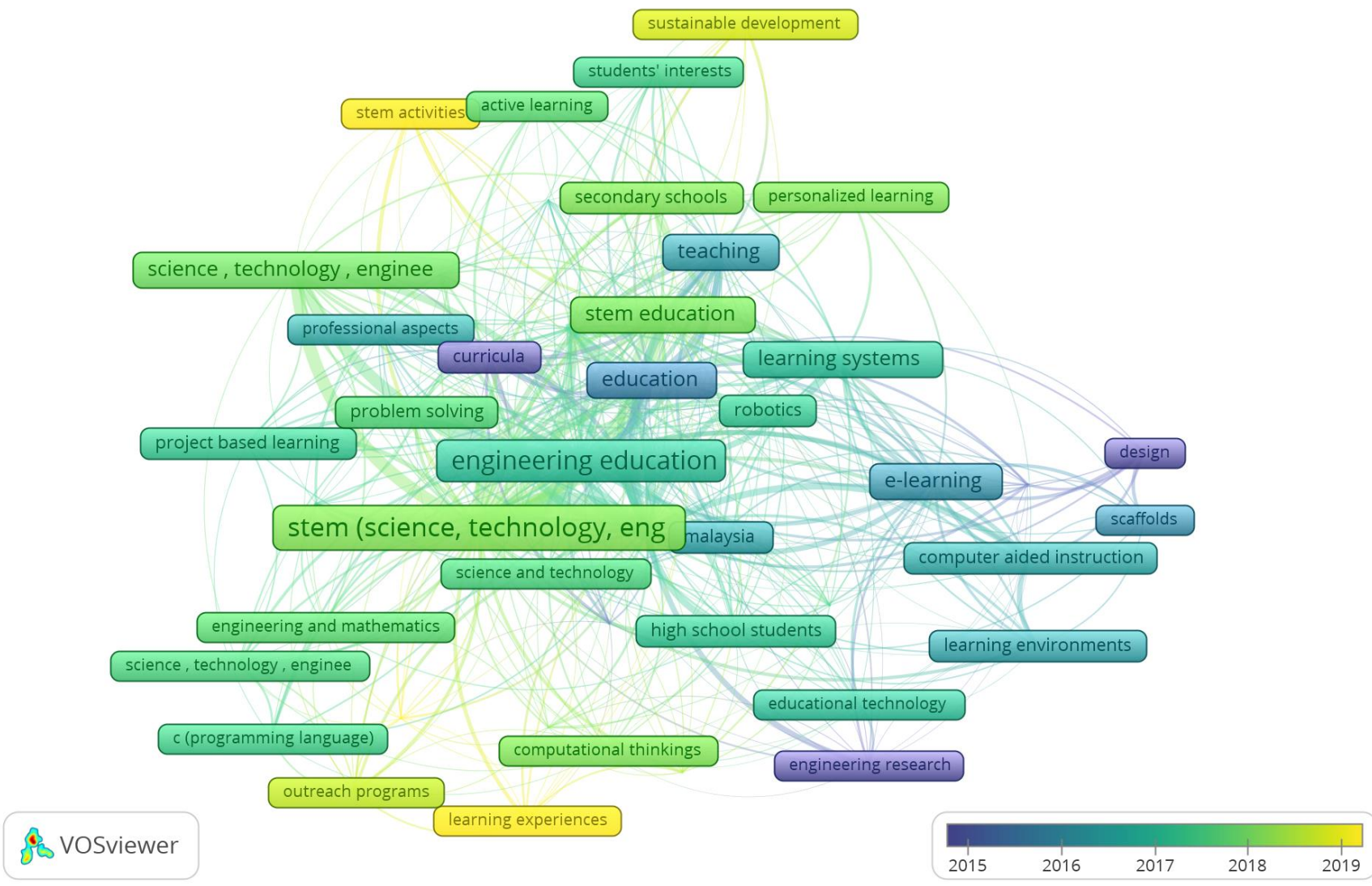

Figure 7. Co-occurrence network with index keywords in the field of STEM education in ASEAN

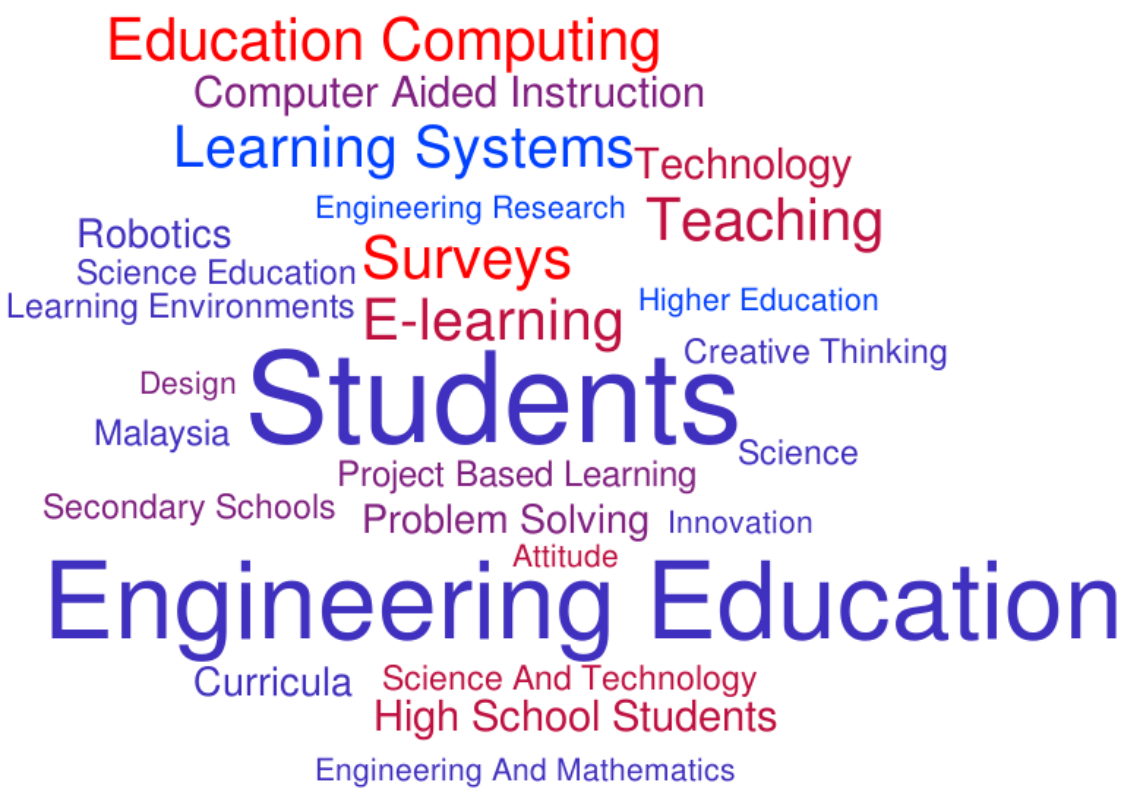

Figure 8. Words cloud (base on keyword) in the field of STEM education in ASEAN

\section{DISCUSSIONS}

Scientific Results of STEM Education in the ASEAN Region have Made Great Progress in the Last Three Years, but Development is Uneven among Countries in the Region

The first research on STEM education in ASEAN started in 2007, although the scientific output in the field of STEM education in ASEAN has only dramatically increased in the last three years (2017-2019). The research that began in 2007, a research on methods to identify variables for predicting STEM enrollment, has the highest number of citations in the field (50 citations) (Nicholls et al., 2007). However, this field received little focus in the following years. Therefore, in the period of 2011-2016, the number of publications relatively 
plateaued. Scientific output in STEM education has only dramatically increased in the last three years (2017-2019) when the number of publications soared and accounted for $67.43 \%$ of the collection. (see Figure 1).

The trend of growth is uneven among countries in the region (see Figure 2). Only 7 out of 11 countries in the region have their journals indexed by Scopus in STEM education and there are four countries with the largest number of publications: Malaysia, Indonesia, Thailand and the Philippines. Malaysia is the leading country, in ASEAN, in terms of scientific output (47.42\%), number of leading training institutions (58.33\%) and number of leading authors (53.85\%). This can be explained by early interest in STEM education from the Government as well as from the Ministry of Education of Malaysia. The term "STEM" was first mentioned by the Malaysian Ministry of Education in the Malaysian education plan (20132025). Shortly afterwards, curriculum at all levels were required to include STEM education as a core element in program development and implementation, emphasizing an intensive approach to teaching and learning based on higher-order thinking skills (HOTS), focusing on demand-based learning, problem solving, contextual learning, cooperation learning, and projectbased learning, all in line with STEM's approach (Bahrum et al., 2017).

\section{The Issue of Intra-ASEAN Cooperation on this Topic is not Really Clear and Effective}

The analysis of cooperation among ASEAN nations demonstrate that scholars in the region have cooperated with 19 other partner countries, but the contribution of non-ASEAN partner countries is not large $(21.74 \%)$. The intra-ASEAN cooperation on this topic is not really clear and effective with results mainly coming from the cooperation of authors from Indonesia, Malaysia, and Thailand (see Figure 3). This also shows the influence of cooperation methods including personnel exchange, information exchange, and institutional change that ASEAN is mainly focused on. Other unused and sporadic methods of cooperation are also carried out separately by ASEAN countries.

When analyzing the contribution of research institutions, it was determined that most researches were conducted by a few strong organizations as $38.44 \%$ of the articles came from the top 10 organizations with the highest number of publications in this field (see Table 2). 7 out of 12 training institutions come from Malaysia, 3 institutions from Thailand, and 2 institutions from Singapore. It can be seen that all three countries are in the top 4 countries with the highest number of articles. The country ranked third with regard to scientific output under the same topic as Indonesia has no representative on this list. Researches from Thailand come from training institutions: KKU, KMUTNB and KMUTT; Singapore focuses on NTU and NIE; Malaysia has a more even distribution deserving of its leading position in STEM education research. Indonesia has the third largest contribution in this field in the region, but researches do not focus on one or several certain training institutions and thus it has a more even distribution compared to other countries. By analyzing the data collected, the authors discovered that there was cooperation among training institutions in STEM education research, but this cooperation was conducted by certain groups of training institutions, and mainly between 2 or 3 main training institutions.

In consideration of author contribution, among the top 10 authors with the most articles in this field 6 authors are from Malaysia, 2 authors from Thailand, and 2 authors are from Singapore (see Table 3). Among them, 7 authors have citations recorded in the Scopus database system more than 100 times, including 4 authors with citations of more than 400 . The two authors who have the most publications in this field are Osman Kamisah and Halim Lilia Bt, both from University Kebangsaan Malaysia, with continuous STEM education research and publishing from 2014 to present. Of the remainder, most have had publications in the last 3 years (see Table 4). This also clearly shows the generally increasing trend of the number of publications in the past 3 years. Cooperation by author group is not plentiful as there are few research groups in the region and there is little connection between groups. (see Figure 6).

\section{Researches on STEM Education in the Region Mainly Focus on Students; the Main Research Fields are Computer Science and Engineering}

When considering the network of keywords analyzed by the VOSViewer software (see Figure 7) and words cloud based on keywords of the published publications on STEM of ASEAN countries (see Figure 8), it can be seen that the main fields with the presence of STEM education research are Computer Science: 59 (33.70\%) and Engineering: 44 (25.10\%). Besides these, we can see that the topics and subjects of research are very diverse. The research subjects mainly focus on students (42); with a much lower number for High School Students (8); while the remaining subjects have hardly any research. The most fundamental and thorough topics focus on Engineering Education; Education Computing. The researches mainly use Surveys (one of the top keywords); keyword analysis also shows that researches focus on teachers' teaching process rather than students' learning process.

While removing the Conference papers it was found that authors sent papers to post in Open Access journal: 41 (38.32\%); Other: 66 (61.68\%). In terms of analyzing trends, an increase in the rate of articles published in Open Access journals was noted. The top 10 journals published $42.06 \%$ of the articles in the collection. ASEAN scholars tend not to submit their works to high-ranking journals: in the top 10 there are no Q1 journals, only 4 Q2 journals with 15 publications (14.02\% of the collection). 
In addition, there are journals recently indexed by Scopus that have not yet been rated by Scimago (Universal Journal of Educational Research) (See Figure 3). These findings show that ASEAN scholars need to improve the quality of their work to meet the standards of high-ranking journals in the field of STEM education.

\section{CONCLUSION}

This paper investigated the academic trend in STEM education literature by means of analyzing the Scopus database, and depicted some characteristics of STEM education literature by using bibliometric and cocitation methods. This paper proposed several findings as followings: (1) Although the first research on STEM education in ASEAN started in 2007, Scientific results of STEM education in the ASEAN region only have made great progress in the past three years, although there is uneven development among countries in the region. (2) ASEAN scholars have cooperated with 19 other partner countries, but the contribution of non-ASEAN partner countries is not large. The intra-ASEAN cooperation on this topic is neither clear nor effective. (3) Researches on STEM education in the region mainly focus on students and the main research fields are Computer Science and Engineering.

\section{LIMITATIONS}

There are some limitations in this study. Firstly, the single use of the Scopus database may not include all scientific articles on STEM Education in ASEAN countries. Using additional bibliographic sources, such as Web of Science and Dimension, will reduce shortcomings in analysis. Secondly, the two most popular and effective bibliographic analysis tools have been used for analysis (Biblioshiny and VOSviewer), but there are some functional limitations that are not possible to overcome at this time, such as statistics of scholars by gender or statistics of new scholars by year. Thirdly, names of authors and their organizations are not standardized in the Scopus database. An author may have several names in different orders, and manual adjustments are not possible. Because the quality of the results are dependent on the quality of input data extracted from the Scopus database, this is the main source of errors in the analysis.

\section{REFERENCES}

Aksoy, B. (2018). The Analysis of Conceptual Development of Stem Education by Bibliometry. November 2017.

Aria, M., \& Cuccurullo, C. (2017). bibliometrix: An R-tool for comprehensive science mapping analysis. Journal of Informetrics, 11(4), 959-975. https:/ / doi.org/10.1016/j.joi.2017.08.007

Bahrum, S., Wahid, N., \& Ibrahim, N. (2017). Integration of STEM Education in Malaysia and Why to
STEAM. International Journal of Academic Research in Business and Social Sciences, 7(6), 645-654. https:// doi.org/10.6007/ijarbss/v7-i6/3027

Batdi, V., Talan, T., \& Semerci, Ç. (2019). Meta-Analytic and Meta-Thematic Analysis. International Journal of Education in Mathematics, Science and Technology (IJEMST), 7(4), 382-399.

Börner, K., Chen, C., \& Boyack, K. W. (2003). Visualizing knowledge domains. Annual Review of Information Science and Technology, 37(1), 179-255. https:// doi.org/10.1002/aris.1440370106

Cobo, M. J., Lõpez-Herrera, A. G., Herrera-Viedma, E., \& Herrera, F. (2012). SciMAT: A new science mapping analysis software tool. Journal of the American Society for Information Science and Technology, 63(8), 16091630. https:// doi.org/10.1002/asi.22688

Friedman, T. L. (2005). The world is flat: A brief history of the twenty-first century (Issue April). Farrar, Straus and Giroux. http://video.mit.edu/watch/theworld-is-flat-9145/

Gonzalez, H. B., \& Kuenzi, J. J. (2014). Science, Technology, Engineering, and Mathematics (STEM) Education: A Primer. Journal of Education and Learning (EduLearn), 7(2), 246-258. https:// doi.org/10.11591/edulearn.v7i2.220

Halim, L., Rahman, N. A., Wahab, N., \& Mohtar, L. E. (2018). Factors influencing interest in STEM careers: An exploratory factor analysis. Asia-Pacific Forum on Science Learning and Teaching, 19(2), Article 1. Retrieved from https://www.eduhk.hk/apfslt/ v19_issue2/rahman/index.htm\#: :text=Explorato ry $\% 20$ factor $\% 20$ analysis $\% 20$ indicated $\% 20$ that, and \%20interest\%20in\%20STEM\%20careers.

Hallinger, P., \& Kovačević, J. (2019). A Bibliometric Review of Research on Educational Administration: Science Mapping the Literature, 1960 to 2018. Review of Educational Research, 89(3), 335-369.

https:/ / doi.org/10.3102/0034654319830380

Hsu, Y.-S., \& Fang, S.-C. (2019). Opportunities and Challenges of STEM Education. In Asia-Pacific STEM Teaching Practices (pp. 1-16). Springer.

Koh, A. (2007). Deparochializing education: Globalization, regionalization, and the formation of an ASEAN education space. In Discourse (Vol. 28, Issue 2, pp. 179-195). Taylor \& Francis Group. https:// doi.org/10.1080/01596300701289144

Le, T. T. H., Tran, T., Trinh, T. P. T., Nguyen, C. T., Nguyen, T. P. T., Vuong, T. T., ... Vuong, Q. H. (2019). Reading habits, socioeconomic conditions, occupational aspiration and academic achievement in Vietnamese junior high school students. Sustainability (Switzerland), 11(18), 5113. https:// doi.org/10.3390/su11185113 
Li, Y., Wang, K., Xiao, Y., Froyd, J. E., \& Nite, S. B. (2020). Research and trends in STEM education: a systematic analysis of publicly funded projects. International Journal of STEM Education, 7(1), Article 17. https:/ / doi.org/10.1186/s40594-020-00213-8

Nicholls, G. M., Wolfe, H., Besterfield-Sacre, M., Shuman, L. J., \& Larpkiattaworn, S. (2007). A method for identifying variables for predicting STEM enrollment. Journal of Engineering Education, 96(1), 33-44. https://doi.org/10.1002/j.21689830.2007.tb00913.x

Özkaya, A. (2019). Bibliometric Analysis of the Publications Made in STEM Education Area. Bartin Üniversitesi Egitim Fakültesi Dergisi, 8(2), 590-628.

Persson, O. (2009). How to use Bibexcel for various types of bibliometric analysis. Celebrating Scholarly Communication Studies.

Promjan, P., \& Ditcharoen, N. (2019). Investigating STEM-based Learning Package for Enhancing Programming and Problem Solving Skills. In L.-H.
Wong, et al. (Ed.), ICCE 2019 - 27th International Conference on Computers in Education, Proceedings (Vol. 1, pp. 209-211). Asia-Pacific Society for Computers in Education.

van Eck, N. J., \& Waltman, L. (2010). Software survey: VOSviewer, a computer program for bibliometric mapping. Scientometrics, 84(2), 523-538. https:/ / doi.org/10.1007/s11192-009-0146-3

van Eck, N. J., \& Waltman, L. (2014). CitNetExplorer: A new software tool for analyzing and visualizing citation networks. Journal of Informetrics, 8(4), 802823. https:/ / doi.org/10.1016/j.joi.2014.07.006

Yu, Y.-C., Chang, S.-H., \& Yu, L.-C. (2016). An academic trend in STEM education from bibliometric and cocitation method. International Journal of Information and Education Technology, 6(2), 113.

Zupic, I., \& Čater, T. (2015). Bibliometric Methods in Management and Organization. Organizational Research Methods, 18(3), 429-472. https:/ / doi.org/10.1177/1094428114562629

\section{http://www.ejmste.com}

